\title{
Derrida y la cuestión de la memoria: el porvenir de un pasado sin Versammlung*
}

\section{Derrida and the Question of Memory: The Future of the Past without Versammlung}

PABLO B. SÁNCHEZ GÓMEZ**

\begin{abstract}
Resumen: La deconstrucción es la apertura al porvenir, hacia el (o lo) otro como porvenir absoluto. Sin embargo, ese (eso) otro se encuentra ante nosotros y tras nosotros, es un pasado por venir, un pasado que nunca ha sido presente. De este modo, la obra de Derrida puede ser leída como la preocupación constante por esa memoria del porvenir, por la herencia y el duelo, por la apertura al acontecimiento. En este sentido, la memoria en Derrida no puede comprenderse como «reunión en el pensamiento», como «Versammlung» y, por tanto, supone quizás una distancia radical en la obra de Derrida con respecto al pensamiento heideggeriano.

Palabras clave: deconstrucción - herencia memoria - duelo - Versammlung
\end{abstract}

\begin{abstract}
Deconstruction is the opening to the future, towards the Other as absolute future. However, this Other is in front of us and behind us, it is the forthcoming past, it is the past without present. In this manner, Derrida's work may be read as the constant main issue about this memory of the future, about the legacy and the mourning, about the opening to the event. Thus, Derrida's memory may not be read as «gathering on the thought», as «Versammlung», and so maybe this is the radical distance between Derrida's work and Heideggerian thought.
\end{abstract}

Keywords: deconstruction - legacy - memory mourning - Versammlung

\section{Introducción}

El presente texto pretende desarrollar una lectura sistemática de la obra de Jacques Derrida tomando como eje la cuestión de una memoria ligada al porvenir que aparece ya desde sus primeros textos. Desde aquí se señalará que, si bien como afirma el propio Derrida, su obra no podría haberse llevado a cabo sin la apertura realizada por las cuestiones heideggerianas, es precisamente con respecto a esta memoria de un pasado como porvenir donde puede comprobarse la enorme, profunda y discreta distancia que separa a Derrida de Heidegger.

Recibido: 26/01/2018. Aceptado: 19/03/2018.

* Esta publicación se integra en el marco del Proyecto de investigación, «Estudio sistemático de las lecturas heideggerianas de Jacques Derrida. Confluencias y divergencias» (FFI2016-77574-P) del Ministerio de Economía, Industria y Competitividad (Dirección General de Investigación y Gestión del Plan Nacional de I+D), co-financiado por la Agencia Estatal de Investigación (AEI) y el Fondo Europeo de Desarrollo Regional (FEDER, UE).

** Investigador predoctoral en la Universidad Nacional de Educación a Distancia (UNED). Líneas de investigación: deconstrucción, filosofía contemporánea, pensamiento heideggeriano. Dirección de correo electrónico: pbsanchezgomez@gmail.com 
De este modo, en la primera parte del texto se iniciará una aproximación al lugar de la memoria en el texto heideggeriano para después confrontar éste con la «mémoire», la herencia y el duelo derridianos.

\section{Erinnerung, Andenken y Gedächtnis en Heidegger}

La cuestión del olvido del ser (Seinsvergessenheit) y de su relación con el recuerdo (Erinnerung) es fundamental desde el inicio de Sein und Zeit. No obstante, ya en sus reflexiones anteriores orientadas al análisis de la vida fáctica dedica Heidegger una atención explícita a la memoria y a su relación con la temporalidad humana. Desde Der Zeitbegriff in der Geschichtswissenschaft y especialmente en Der Begriff der Zeit Heidegger distingue una temporalidad como medium homogéneo, tiempo de los relojes, de índole cualitativa, lo cual es señalado también en Einführung in die Phänomenologie der Religion a través de la lectura de las epístolas paulinas y del tiempo del kairós. Sin embargo, es necesario destacar del tratamiento heideggeriano de la memoria en estos primeros escritos el texto Augustinus und der Neuplatonismus, donde se detiene en la aporía del olvido (que la «oblivio» sea y al mismo tiempo no pueda ser en la «memoria»). No obstante, aun cuando en estos textos se anticipa en gran medida la analítica existencial de Sein und Zeit ${ }^{1}$, «durante este periodo temprano de su trabajo, Heidegger no hace una distinción terminológica entre los dos términos alemanes para "memoria", "Erinnerung" y "Gedächtnis"» (Barash, 2008, 402). Es ya en Sein und Zeit donde Heidegger, a través de la distinción o del binomio compuesto por el «concepto vulgar del tiempo» y el «tiempo original», siendo éste esenciado en la resolución (Entschlossenheit) desde la caída (Verfallen), donde Heidegger plantea el lugar fundamental de la memoria en la constitución del Dasein, señalando que «así como la espera únicamente es posible sobre la base del estar a la expectativa, así lo es el recuerdo (Erinnerung) sobre la base del olvidar y no a la inversa, pues en el modo del olvido "abre" el sido primariamente el horizonte dentro del cual puede recordar el "ser ahî" perdido en la "exterioridad de aquello que se cura» (Heidegger, 1977a, 449). El olvido es, por tanto, el horizonte, el fondo o el suelo sobre el que puede alzarse el recuerdo, y no un mero accidente sobrevenido a una memoria plena.

En este estado de resuelto el Dasein hereda un mundo que debe reiterar (Wiederholung): la historia no es «vorhanden», una mera restauración (Wiederbringen), sino respuesta (erwiedern) y retorno (Wiederkehr) (Cfr. Heidegger, 1977a, §74) que afirma la «Destruktion» como «un regreso fecundo al pasado en el sentido de una creadora apropiación de él» (Heidegger, 1977a, 29). De este modo, Heidegger abre en Sein und Zeit la posibilidad de comprender el origen y su recuerdo en la memoria como tarea, lo que le permitirá afirmar en el año 1941 que «el recuerdo (Erinnerung) del inicio (Anfang) no es, por ello, una huida al pasado, sino prestancia al porvenir» (Heidegger, 1991, 21). La cuestión de la memoria del inicio (Anfang) conduce a Heidegger, en sus trabajos de los años 30, a distinguir a éste del comienzo (Beggin), así como el «primer inicio» (ersten Anfang) del «otro inicio» (anderen Anfang), pudiendo de este modo afirmar que «nunca conduce el recuerdo (Erinnerung) del primer inicio a regresar "detrás" de éste, sino a avanzar desde su intimidad al otro inicio

1 Para una lectura detallada de estos cuatro textos de Heidegger y de su influencia en la obra posterior de Heidegger, Cfr. Esposito, 2009. 
(ocaso)» (Heidegger, 2005, 91). Los «objetos» de la memoria no son ya pasados, si por tal se entiende «instantes» originales y causales, sino un inicio (Anfang) como ocaso (Untergang) desde el que puede desarrollarse un «pensar preparatorio» (Vordenken) del otro inicio. Esta noción del recuerdo y de la historia, de cierta memoria histórica, que se encontraba incipientemente en Sein und Zeit, se consolida ahora a través de la distinción entre «Historie» (historia impropia, anhelo de las «causas») y «Geschichte» (historia acontecida en cuanto destinación) (Cfr. Heidegger, 1997a, 442).

Desde este periodo de su obra, que podríamos denominar con Krell metaphysical remembering (Krell, 1990, 262), Heidegger enuncia que el inicio (Anfang) propicia el comienzo (Beggin) susceptible de reapropiación en el recuerdo, siendo ese inicio mismo la aclaranteocultación de la Verdad (Aletheia) en cuanto esencia (west) en el despido (Entlassung) y, por tanto, inalcanzable como tal para el recuerdo al que ha dado lugar: «el inicio se oculta en el comienzo», afirmará años más tarde (Heidegger, 2002, 156). De este modo, el inicio, el verdadero objeto de la memoria, es abismo (Ab-grund) que dirime (Austrag) el ente en la despedida, esto es, en modo alguno un objeto, por lo que todo recordar (Erinnerung) de ese inicio no puede ser sino un preparar el pensamiento (Vordenken) a esa epocalidad del ser que abre la historia (Geschichte) del (genitivo objeto y subjetivo) ser en cuanto destino (Geschickt), es decir, un recuerdo sin apropiación. La memoria, por tanto, no dispone de objetos históricos (Historie), sino que se orienta hacia una permanencia (Bleiben) de la donación (Verschenkung) como rechazo (Verweigerung), hacia un olvido necesario. La verdad, en cuanto inicio, aclara y oculta; es el «claro para el ocultarse» ${ }^{2}$ y, por tanto, no puede ser reapropiado como objeto en la memoria por constituir el espacio inicial (Anfang) para toda reapropiación de los comienzos (Beggin). Siendo el inicio (Anfang) abismo y ocultación, todo acercamiento a través de la memoria es un adentrarse en el esenciar (west) más profundo y lejano en la diferencia decisiva (Austrag), por lo que el olvido del ser en el progreso en cuanto época de la historia del ser, es decir, en la entrega máxima del ente y en el desplazamiento de la esencia del hombre a mero gestor de éste puede dar el impulso decisivo de la memoria del inicio (Cfr. Heidegger, 2005, 176). Si en Sein und Zeit afirmaba Heidegger el olvido como sustrato para el recuerdo, ahora se comprende el primero como el objeto al que se aproxima el segundo.

Para Heidegger, el hombre se encontraría precisamente en esa época de la imagen del mundo en la que el abandono del ser se consuma y realiza en el dominio sobre y de lo ente, en la voluntad de voluntad en cuanto clausura de la historia nihilista de la metafísica: «con la asignación y destinación del ser como enfrentamiento objetual (Gegenständigkeit) comienza la más extrema retirada del ser» (Heidegger, 1997b, 131). De este modo, siendo el inicio retirada que esencia (west) «como» fundamento (Grund) abismal (Ab-grund), el hombre no puede sino pensar esa «dadivosa propiedad» del inicio a través del recuerdo (Erinnerung) de su retirada, de su ocultación u olvido. Será a través de los seminarios dedicados a Hölderlin como Heidegger tematizará con insistencia la esencia de la memoria del inicio, y lo hará sustituyendo el término «Erinnerung» por «Andenken», afirmando que este último es

2 «La verdad: el claro (Lichtung) para el ocultarse (es decir, el acaecimiento (Ereignis); vacilante rehusarse como la madurez, fruto y obsequio). Pero verdad, no simplemente claro, sino precisamente claro para el ocultarse (...) La verdad: fundamento como abismo (Grund als Abgrund)». M. Heidegger, 1989, 346. 
un pensar en (Denken an) lo «sido» (Gewesene) como porvenir que sigue siendo y no lo pasado (Vergangenen) irrevocablemente en cuanto presente-pasado (Cfr. Heidegger, 1981, 84). Como señala Gadamer, con el término «Andenken» puede Heidegger separarse del mero «recuerdo» como tener-presente-algo para orientar su reflexión hacia una memoria del «pensar-en» que permite así una riqueza y multiplicidad del recordar ( $C f r$. Gadamer, 1999, 155-156).

El río Ister, que parece avanzar hacia atrás, hacia el oeste, es memoria del inicio: «Wie du anfingst, wirst du bleiben». A lo largo de los seminarios dedicados a la poesía de Hölderlin, en especial a su «poesía fluvial» e «Himnos», Heidegger insiste en que, si el inicio está por venir en cuanto esencia, origen, tierra natal $(\text { Heimat })^{3}$ y fuente, siendo estos «lo mismo» son, por tanto, lo más lejano y distante pues, retomando los versos de Hölderlin, «nemlich zu Hauß ist der Geist / Nicht im Anfang, nicht an der Quell». Ahora bien, es en esa extrañeza o «destierro» donde el hombre puede pensar en (denken an) su memoria (Andenken) el origen desde el «valiente olvido» (tapfer Vergessen) (Cfr. Heidegger, 1993, 164-165). Porque la memoria piensa en un inicio (Anfang) como lo «puramente brotado» (Reinentsprungenen) que permanece (Bleiben) sin encontrarse presente, que esencia en lo brotado (Entsprungene) y en el ser-brotado (Entsprungensein) en cuanto «bienaventuranza del enemigo» (Feindseligkeit als Seligkeit) (Cfr. Heidegger, 1999, 241). La memoria, por tanto, no se orientaría hacia una fuente que recordar, un «comienzo», sino al inicio (Anfang) que, como señala Heidegger al comienzo de su curso del año 1934, es algo absolutamente distinto (Cfr. Heidegger, 1999, 3): el inicio no es dejado atrás en lo por él iniciado y, por tanto, no puede ser reapropiado en el recuerdo (Erinnerung) al no haberse desgajado o perdido en ningún momento.

El río es el misterio (Geheimnis) de la proximidad de lo distante (Cfr. Heidegger, 1981, 24), de la fuente, y al mismo tiempo la localidad para el habitar de los hombres (Cfr. Heidegger, 1993, 51): «Hier aber wollen wir bauen». De este modo, el río en cuanto memoria de su inicio y localidad-travesía (Ortschaft-Wanderschaft) determina el encontrarse en lo propio, en el hogar (Heimischsein) de los hombres como un llegar a ser en casa (Heimischwerdens) (Cfr. Heidegger, 1999, 51) y, por tanto, la reapropiación de lo propio en el recuerdo como un encontrarse en camino hacia y como la memoria (Andenken). De nuevo, Heidegger señala con esto que el recuerdo de lo propio sólo es aproximable asumiendo su distancia desde lo extraño al hogar (umheimisch), desde la colonia, desde el mar y desde el olvido. Pero ahora sostiene que la memoria, en cuanto «Andenken», no es una posesión del recuerdo (Erinnerung) del comienzo, sino el saludar (Grïßen) (Cfr. Heidegger, 1981, 96) que piensa en (An-Denken) la esencia del río, en su propiedad y en su fuente como necesariamente distante y, por tanto, es la memoria (Andenken) la afirmación y el esenciarse de esa distancia misma en el pensamiento y como pensamiento. La memoria (Andenken) no es, de este modo, la disponibilidad interiorizante del recuerdo (Erinnerung) ${ }^{4}$, sino un ponerse en obra hacia el olvido.

3 Para una lectura detallada de la cuestión de la «tierra natal» en Heidegger, Cfr. Rocha de la Torre, 2012. Asimismo, Cfr. McNeill, 1999.

4 Si bien es cierto que Heidegger desplaza el término «Erinnerung» por «Andenken», este movimiento no se produce en un solo acto. Así puede comprenderse que, en el curso sobre El Ister, posterior a Andenken, Heidegger emplee, para referirse a la esencia de este río, el término «Erinnerung», aun cuando intenta separarlo de su 
Como señala Heidegger en otros textos, desde el momento en el que lo que se nos da es el dar-se, no puede haber distinción sino mismidad entre el habitar y el construir, el cuidar y el ser: albergamos porque ya habitamos y porque, en cuanto que habitamos, construimos ${ }^{5}$. La memoria, por tanto, no crea el fundamento, como el saludar no puede sino re-dirigirse a lo saludado. La fundamentación que «dice» el poeta, por tanto, es un re-decir el fundamento, la fuente: «poetizar es hacer memoria (Dichten ist Andenken). La memoria (Andenken) es fundación. El morar fundante del poeta indica y consagra el fundamento para el morar poético de los hijos de la tierra. Algo que permanece llega a permanencia. Hay memoria (Andenken ist)» (Heidegger, 1981, 151). De este modo, el decir del poeta es un re-decir la fuente, un repetir lo dicho «del» ser que se ha aprendido en la memoria, par coeur ${ }^{6}$ : el decir del poeta es, por tanto, la memoria que (se) funda. El ser, como fuente, habla. El poeta, en cuanto dice, repite y funda. Esto conduce a Heidegger a señalar la esencial vinculación entre la memoria (Andenken) en cuanto que piensa en (Denken an) el ser y recibe de él su esencia y el agradecer (Danken) (Cfr. Heidegger, 1976, 310), encontrando el modo esencial de su vinculación en el término «Gedanc», «el recordar reuniendo, que lo reúne todo» (Heidegger, 2002, 143). De este modo, y aun cuando, como señala Haar, la vinculación entre los términos «Gedächtnis», «Dichten», «Denken» $\mathrm{y}$ «Andenken» es tan esencial que resulta confusa su utilización (Cfr. Haar, 1993, 71), Heidegger comienza a hacer pivotar su reflexión sobre el término «Gedächtnis»:

La memoria (Gedächtnis). Sin duda esta palabra significa algo más que la simple facultad psicológicamente constatable de retener lo pasado en la memoria. La memoria piensa en lo pensado (Gedächtnis denkt an das Gedachte). Ahora bien, «memoria» (Gedächtnis), como nombre de la madre de los dioses, no significa un pensamiento cualquiera de cualesquiera cosas pensables. Memoria (Gedächtnis) es la concentración (Versammlung) del pensamiento (Denken) en aquello que por doquier haya podido ser pensado ya. Memoria (Gedächtnis) es reunión (Versammlung) del pensamiento (Andenken) [...] La memoria, la madre de las musas, el recuerdo (Andenken) de lo que ha de pensarse, es la fuente de donde mana el poetizar (Dichten). Por eso, la poesía (Dichten) es el agua que a veces corre hacia atrás, hacia la fuente, hacia el pensamiento (Denken) como memoria pensante (Andenken) (Heidegger, 2002, 13).

La memoria (Gedächtnis) en cuanto pensar (gedenken) es la reunión (Versammlung) «del» pensamiento (Gedanke), «reunión» que, como señala Heidegger, recibe para los griegos el nombre de «legein» (Cfr. Heidegger, 2000, 214-217), esto es, un recolectar, reunir (Sammeln) que deja yacer aquello que ha sido puesto y «percibido» (noein) delante como eso mismo que yace delante (Cfr. Heidegger, 2002, 211-215). Por tanto, en cuanto «legein» es asimismo «enunciar» como poner-delante, esto es, Decir (Sage) como Mostrar (Zeigen) (Cfr.

noción vulgar al hablar de un «auténtico recuerdo» (eigentliche Erinnern) orientado a lo sido (Gewesenen) en cuanto presentimiento (Ahnen). Cfr. Heidegger, 1993, 34.

5 Cfr. Heidegger, 2000, 149-151; 206.

6 La cuestión del corazón y su relación con la memoria es tratada explícitamente por Heidegger (Cfr, Heidegger, 1981, 75; 1977b, 305-312; 2000, 207; 2005, §138-§141). Para una lectura global del lugar del corazón en el pensamiento heideggeriano, Cfr. Wood, 2015. 
Heidegger, 1985, 242), todo percibir (noein) lo es de un «legein», un «presente» («દ่óv», «Anwesende») puesto-dicho. Ahora bien, este dicho-presente es tal desde una «presencia»

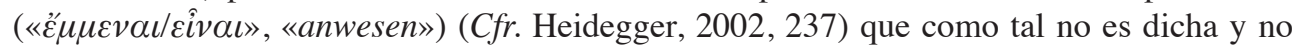
puede confundirse con lo dicho. Y de este modo, la memoria que dice y se dice a sí misma no puede, en última instancia, hacer memoria de su propio inicio, convertirlo en un recuerdo. El poeta, en cuanto hace memoria, es el vidente para quien «todo lo presente y lo ausente está reunido en una presencia resguardada en ella» (Heidegger, 1977b, 364), es decir, quien preserva este «ver» y lo pone en obra en su memoria (Andenken) sin poder enunciarlo como recuerdo (Erinnerung). El saber es, por tanto, el pensar en la memoria el paso, el «entre» (Zwischen) o «medio» (Mitte) que reúne (Versammlung) y co-liga en cuanto separa: «Austrag», pero que como tal no puede constituirse en recuerdo de «algo». A esta relación de la diferencia que reúne la denomina Heidegger «Unter-Schied» $(C f r$. Heidegger, 1985, 22), esto es, el aporético objeto de la memoria.

Ahora bien, si el ser Dice, Muestra, y el pensar («noein») es un percibir y salvaguardar en la memoria este decir en cuanto lo pone-delante, el pensar es, asimismo, un decir, un redecir o, como dice Heidegger, «omo-logein» (Cfr. Heidegger, 2000, 225-226). De este modo, Heidegger señala que el hablar de los hombres (Sprachen) muestra y, como tal, realiza un trazo (Riss), pone en obra la memoria, pero este hablar es siempre un escuchar (hören) a aquello a lo que el hombre pertenece (gehören), es decir, al Decir del ser, al trazo-abriente (Auff-Riss) impronunciable e indecible que aporta su riqueza a todo lo dicho, irremontable para cualquier memoria: «el hombre es en su esencia la memoria del ser (Gedächtnis des Seins), pero del ser tachado», es decir, del necesario olvido (Cfr. Heidegger, 1976, 411). De nuevo, los múltiples modos de decir de los hombres no se diseminan, sino que encuentran su permanencia en la reunión (Versammlung) de un inicio (Anfang) que es inaccesible a la memoria, una fuente y una tierra natal que no son sino destierro y corriente: todo parece depender, en definitiva, de la reunión, de su decirse en y como la memoria. El hombre, por tanto, hace memoria en su palabra, pero no posee el recuerdo de ésta: la palabra es el recuerdo en el que el «Es» del «Es gibt» canta (melos) (Cfr. Heidegger, 1985, 249). La memoria, por tanto, no lo es de un pasado que ha sido presente, sino de un porvenir que viene continuamente. Como se señalará más adelante, quizá la memoria en Heidegger pueda comprenderse, por tanto, como «promesa». Porque si, como ya se señalaba en Sein und Zeit, el olvido es el fondo para el recuerdo, ahora se comprende que olvido y recuerdo son lo mismo: el decir como hacer memoria interminable, como porvenir. La memoria, por tanto, sólo puede esenciarse desde el único recuerdo, el único olvido que tienen hasta ahora los hombres: la metafísica.

\section{Derrida y la mémoire sin Versammlung}

Desde sus primeros textos Derrida «solicita» la idea de una memoria como reapropiación sin residuos, consumada, consumida, del pasado. Como señala ya en un texto temprano, desde que toda presencia conlleva una «retención» y una «protensión» no se puede hablar de presencia «plena» sino de huella (trace) como «condición» de cualquier presencia, una «huella originaria» o «archi-huella» $(C f r$. Derrida, 1985, 121) en cuanto continuo remitir a otro que originaría el presente y que, por esto, invalidaría la idea misma de un «origen» estanco 
y definitivo reapropiable en el recuerdo. En este sentido, la huella no «es», no «es» «algo», sino que (es) el movimiento de «espaciamiento» en cuanto «devenir-espacio del tiempo» y «devenir-tiempo del espacio» en el que esa «brisure» y «borde» (Cfr. Derrida, 2011, 53) posibilita la aparición de cualquier sentido. Hay una no-presencia continuamente borrada o desplazada que permite el anhelo arquetele(te)ológico en el que la memoria se remontaría al origen «pleno», sin diferencia, dinámica propia «del» «fono-logocentrismo». El «origen» no «es», la «différance» es el origen como «archi-escritura» en cuanto movimiento de la significación que inscribe en el «presente» un «pasado» y un «futuro» absolutos, «no-presentes», no susceptibles de una memoria fundamentada en la primacía del «ahora», «es»o «nun», esto es, una memoria de la presencia.

Que ningún «presente» sea idéntico a sí mismo sin la «huella» de (un) otro es algo que «la metafísica» no quiere escuchar: su memoria desea abrazar y conservar los recuerdos custodiados en la proximidad sin posibilidad de pérdida. Una buena memoria, «Mneme» del Bien y del Padre consistiría, pues, en una representación sin distancia ni intermediación externa, puro «oírse-hablar» sin contaminar por esa «mala» memoria que es el instrumento técnico de la «hipomnesis», que sepulta y conmemora el alma en el signo, el archivo sumiso que desea que las piedras hablen (Cfr. Derrida, 1997a, 98-102). Ahora bien, una memoria infinita no es una memoria, sino un constante asistir de la presencia, por lo que ésta, para ser tal memoria, necesita «signos», ese «farmacon» que hará «dormirse» a la «Mneme» y distanciará sus recuerdos. «El» logocentrismo sueña con la memoria plena, con la autoridad frente a los signos, encontrando su límite y la «suplencia» en su propio interior. Así, ante lo inevitable del signo, «la» metafísica pretendería su «digestión» o «biodegradación» que permitiría la liberación del vaho prístino de una «Bedeutung» sin materia significante. Ahora bien, asegurar la descomposición de cara a una «parusía» implica la monumentalización de la tumba, su localización, la protección frente a la diseminación y los muertos que vagan más allá de sus tumbas ( $C f r$. Derrida, 1995a, 23). Sin embargo, si lo propio del signo es poder producir efectos con independencia de la intención que los anima, el recuerdo, y si la memoria tiene siempre necesidad de signos, la idea de «un» recuerdo puro, unitario y garantizado se encuentra anulado por la propia posibilidad de la huella archivante (Cfr. Derrida, 1997a, 105-106). La asimilación nunca llega a realizarse plenamente imposibilitada por la (a)lógica de la huella y la iterabilidad, por lo que el cuerpo nunca llega a descomponerse, «repite», se repite y ofrece resistencia: es lo que Derrida llama «ceniza(s)» (cendre) que, como afirma una de las voces en Feu la cendre, es el «paradigma de la huella» (Cfr. Derrida, 2009a, 29) y en modo alguno las cenizas del Fénix. De este modo, el «efecto de restancia», que es la incineración de la incineración misma en cuanto resto de algo que no es, imposibilita toda «Erinnerung» que asuma la posibilidad de una digestión pacificada ${ }^{7}$, abriéndose así el pensamiento de la memoria en Derrida hacia la «Andenken» heideggeriana. De este modo, sólo es posible la diseminación como sobrevida de la huella, no siendo ésta una alternativa a la muerte o a la vida (Cfr. Derrida, 2003a, 322-323; 2011, 46-47).

La memoria para Derrida, por tanto, no tiene recuerdos, sino cenizas, fechas que hacen retornar aquello que ocurrió una vez, y sólo una vez (Cfr. Derrida, 1974, 271-272A). Ahora

7 Esta «retórica del canibalismo» es algo recurrente desde Glas (Cfr. Derrida, 1974, 40b). Por otra parte, Cfr. Derrida, 1993, 269-303. 
bien, como ya había señalado con respecto a la construcción de los objetos ideales en Husserl, la fecha se encuentra en una «aporía», pues para ser tal debe poder repetirse y, por tanto, que aquello que fecha no se encuentra ya más presente. Este es, por tanto, el «double-bind» de la fecha, un secreto que no por desvelarse resulta menos secreto: si lo que conmemora la fecha es encriptado, esto se perderá en cuanto la singularidad desaparezca y ya no feche para nadie, pero si es demasiado general la singularidad se pierde en la universalidad, por lo que la fecha es la «legibilidad de lo ilegible»: «desde ese momento, lo que debe conmemorarse, a la vez reunir y repetir, es, al mismo tiempo, el aniquilamiento de la fecha, una especie de nada, o ceniza» (Derrida, 2002, 31). Aniquilamiento de la fecha, pero también del nombre propio, de aquel que firma en su nombre ${ }^{8}$, es decir, la cuestión de la «iterabilidad» $(C f r$. Derrida, 2003a, 307-308): desde el momento en que hay nombre «es siempre y a priori un nombre de muerto» (Derrida, 2009b, 34) que producirá efectos aun cuando el portador desaparezca, no siendo posible suturar ni saturar el contexto; es más, exige la muerte, en cuanto «no depender-de-ni-retornar a», de la instancia donadora ( $C f$ r . Derrida, 1995b, 102103), la incineración, el «brûle-tout». Como sucedía en Heidegger, y lo desarrollaremos más adelante, la memoria en Derrida deviene un pensamiento del don.

El nombre es la ceniza, el resto que sobrevive al portador aun antes de su muerte $(C f r$. Derrida, 2008, 62) por lo que, como señala Derrida, sólo ingenuamente podría pensarse que la memoria se orienta al pasado: en cuanto la muerte antecede al portador del nombre, éste no es sino (en) la memoria del otro como porvenir. Ahora bien, he aquí otra «aporía»: la fidelidad al otro implica asumir como tal «otro» en la interioridad de uno mismo y, por tanto, en cuanto «otro» que no puede estar «en mí». De este modo, señala Derrida, debe asumirse la «imposible afirmación del duelo», la afirmación de su im-posibilidad y aceptar la «experiencia de la aporía», la experiencia interminable de la decisión y de la memoria: el deber, en este caso de duelo, es de lo que no se puede deber, es decir, de lo que debe más allá del poder y del deber ${ }^{9}$. Porque un duelo posible o un deber que responde a lo que se debe no es ni duelo ni deber alguno sino la aplicación de un saber programado y programable; la memoria, en cambio, es la experiencia de la aporía en la que «hay que evitar a toda costa la buena conciencia» (Derrida, 1998a, 40).

Siendo la huella del otro originaria y siempre «otra», la memoria como imposible clausura de ese «otro» precede y constituye al individuo: «je suis endeuillé donc je suis» (Derrida, 1993, 331), es decir, llevo al «otro» y su «mundo» antes de ser «yo», soy el rehén que hospeda al «otro». De este modo, no hay en Derrida una «Erinnerung» absoluta que se apropiase del «pasado»: la supervivencia lo es de un pasado absoluto que no ha tenido lugar, una promesa que com-promete sin «asegurar» (Cfr. Derrida, 2008, 103-109). La memoria, como sucedía en Heidegger, es el lugar de la huella como recuerdo imposible, por lo que ésta se dirige a un «pasado» que no ha tenido lugar, un «presente» que comienza por regresar, hacia un cuerpo sin unidad, sin cuerpo pero tampoco «nada», hacia «espectro(s)», de los que dice Heidegger que son «porvenir» $\square$. El espectro, como las cenizas, señala Derrida, nos asedia y se nos presenta sin presencia, sin poder ser reducido a «algo» ni afirmado

8 Esto es algo que Derrida presenta ya desde sus textos tempranos: Cfr. Derrida, 1986, 89 y Derrida, $1994,370$.

9 Derrida señala como «imposibles» la deconstrucción, «el don, el sí, el "ven”, la decisión, el testimonio, el secreto, etc.» (Derrida, 2011, 27). 
como «nada», mirándonos sin poder ser identificado en su «propiedad». En este sentido, la «figura» del espectro no puede sino relacionarse con la aporía del don: para ser tal, éste no debe darse como «algo», algo «presente», sino que más bien debe dar-se una «nada» o un «olvido» (Cfr. Derrida, 1974, 270A). Porque el don no «es», se da (si lo hay) como borrarse en y como lo dado. Hay en lo dado, por tanto, una inaccesibilidad de la memoria frente a la donación misma, tal como sucede con la donación del ser en Heidegger ( $C f r$. Derrida, 1995b, 35), es decir, que desde ahora podemos comprender «la ceniza como la casa del ser» (Derrida, 2009a, 27). A la memoria se le da nada, un olvido radical, una huella como ceniza, un espectro al que ya no podemos más nombrar «directamente», «propiamente», sino sólo con «palabras oblicuas» en dirección «destinerrante». La memoria se enfrenta a un movimiento catastrófico, «catastrópico» en la que eso que da no hace sino borrarse retrazándose de nuevo en retirada (Cfr. Derrida, 1987, 87-93). Si antes se señaló que el pensamiento de la memoria se abría en Derrida a un pensamiento del don, ahora se comprende que este último no es sino la memoria del olvido. Por lo tanto, el pasado de la memoria es el porvenir, un porvenir que repite, sin duda, pero aquello que nunca ha tenido lugar, sino que se encuentra frente a nosotros como porvenir y como tarea (Cfr. Derrida, 1995a, 31).

La memoria, por tanto, es para Derrida una herencia que crea tanto como registra, que crea en cuanto registra y que, de este modo, no dispone de un «stock mnésico» esperando ser retomado, sino que el espectro se nos da como reto y tarea: «heredar no es en esencia recibir algo, un elemento dado, que entonces se puede tener [...] Cuando se hereda, se clasifica, se criba, se valora, se reactiva» (Derrida, 1998b, 40). Hay una falta en eso que se da, en ese resto o ceniza; una falta que hace falta, que abre la posibilidad de la respuesta y de la responsabilidad. La memoria es, por tanto, recepción, «sí» anterior a cualquier respuesta dirigida al otro, pero también reafirmación, reinscripción, «sí, sí» a lo que viene necesariamente sin haberlo escogido en cuanto promesa (Cfr. Derrida, 1987, 639-650). La memoria hereda, afirma, retoma, pero siempre escogiendo, cribando esa herencia que nunca es una, que nunca se re-úne, posibilitando en esa «repetición», por tanto, una nueva aporía, lo imposible de un cortocircuito entre lo constatativo y lo performativo en una «invención» ( $C f r$ Derrida, 1987, 61). La memoria es repetición e invención, selección y respuesta. En este sentido, la memoria es infinitamente responsable ante cada «otro» por haber seleccionado «un» otro, por haber escogido a «ese» otro (Cfr. Derrida, 2000, 72). La memoria en Derrida es, por tanto, infinita en infinitos sentidos: sin origen, sin objeto, infinitamente responsable, abierta al porvenir absoluto, pero también infinitamente finita, humilde, paciente, constante (Cfr Derrida, 2003a, 310). De este modo, Derrida presenta una memoria que no se realiza en el recuerdo (Erinnerung), que quizá haya que pensar como lo «otro» del recuerdo, como el hacer memoria sin recuerdo, como «Andenken».

En este sentido, la cuestión fundamental no podría retrasarse más: ¿es la memoria como porvenir subsumible a la memoria (Andenken-Gedächtnis) heideggeriana? ¿Piensan ambos «lo mismo» en un «querer-decir» universal bajo los términos «mémoire» y «Gedächtnis»? Porque aceptando que tanto Heidegger como Derrida toman distancia de un «comienzo» aprehensible o representable en la «presencia-presente» de la «Erinnerung», aproximándose así ambos a un «inicio» sin pasado, esto es, una «huella», de la que Heidegger dice que es la «más matinal» (die frühe Spur), aceptando esto, cabría plantearse si es «idéntico» ese «pasado sin presente» en Heidegger y Derrida, teniendo en cuenta, por otra parte, que «este» 
inicio no dispone de nada «propio»y, por tanto, no puede resultar «idéntico». En este sentido, la cuestión consistiría en saber desde qué perspectiva se accede a una puesta en común del lugar de la memoria en sus obras y, por tanto, si el porvenir de Heidegger pasa a través de la memoria de los textos de Derrida. Ahora bien, responder a esta cuestión supondría abrir un gran campo interrogativo que pasaría por la relación entre la «Destruktion» y la «deconstrucción», entre la «sigética» y la «Zusage» heideggeriana y el «sí» derridiano; entre la «khôra»y el «Raum» o el «Ort» en Heidegger, el «Zeit-Spiel-Raum» y el espaciamiento de la «différance», el «Wink» y la «brisure». Pensar, en definitiva, si el «trait» como «retrait» en el texto de «la» metafísica puede comprenderse desde el «Riss» en el «Aufriss» que se retira hacia lo irremontable, si el saludo que toma Heidegger de Hölderlin es idéntico al que entrega Derrida a Lévinas.

Sin embargo, Derrida mismo ha emprendido un acercamiento al texto heideggeriano que puede en gran medida presentar una comparación del lugar de la memoria en la obra de ambos. Antes se dijo que la memoria en Derrida resultaba infinita y que, por tanto, quizá podría comprenderse como la «Andenken» heideggeriana. Sin embargo, Derrida toma distancia de esta posibilidad al señalar que la interminable memoria no lo es porque su recuerdo resulte demasiado rico y digno como para «darse» de forma definitiva, es decir, en una «Versammlung» rememorante que no podría llegar a cerrarse. De este modo, Derrida cree encontrar en Heidegger cierto tono melancólico de una memoria que no es capaz de llegar a cerrar el recuerdo, es decir, cierta actitud «logocéntrica» que primaría la reunión (Versammlung) (Cfr. Derrida, 1998c, 374) y que imposibilitaría la irrupción de lo heterogéneo al recuerdo (Erinnerung), es decir, la memoria (Cfr. Derrida, 1987, 181). Sin embargo, es el propio Derrida quien complica las cosas al señalar que la «Gedächtnis» como «Versammlung» del pensar (Gedanke) no es sencillamente monológica, es decir, no es sólo el recuerdo hablando de sí en infinitas reapropiaciones, pero tampoco heterológica, esto es, lo otro del recuerdo, sino una «auto-heterología» del habla (Sprache) consigo misma a través de su distinción (Austrag) (Cfr. Derrida, 1998c, 404-406; 2011, 44): la memoria heideggeriana, por tanto, sin ser recuerdo no podría ser sino en recuerdos. Se comprueba ahora que la cuestión de la memoria deviene así la pregunta por la lengua de la memoria, es decir, por la lengua de la diferencia con y en el recuerdo. Pregunta a este respecto Derrida:

¿se puede y hasta dónde se puede pensar esta marca y el des- de la différance como Wesen des Seins? ¿El des- de la différance no nos lleva más allá de la historia del ser, más allá de nuestra lengua también y de todo lo que en ella puede nombrarse? ¿No apela, en la lengua del ser, a la transformación, necesariamente violenta, de esta lengua en una lengua totalmente diferente? (Derrida, 1994, 60).

Esta «lengua» lo sería de la inscripción de la huella como (no) origen, esto es, una lengua «hipermnésica» en cuanto se dirigiría a un pasado más allá de cualquier presente, más allá de cualquier recuerdo, «preprimera lengua», una lengua anterior a cualquier «yo» y por tanto una lengua del absolutamente otro «en» mi lengua, al otro porvenir y al otro como porvenir. Y aun cuando Heidegger, ciertamente, apela a la «Urwort», dejando así en su tono la posibilidad de comprender ésta como «hiper-recuerdo» más que como «hiper-memoria», Derrida señala que «esto no quiere decir que la lengua sea monológica y tautológica, sino 
que siempre corresponde a una lengua invocar la apertura heterológica que le permita hablar de otra cosa y dirigirse al otro» (Derrida, 1997b, 111). Cabría destacar que aquí Derrida ya no apela a una «auto-heterología» en Heidegger.

De este modo, aun cuando Derrida señala que Heidegger, «como siempre», prima la «Versammlung» y por tanto dejaría entrever una comprensión de la lengua de la memoria como destino del hiper-recuerdo, es decir, encaminada todavía hacia la reapropiación de la «Erinnerung», es el propio Derrida quien afirma que «el pensamiento de Heidegger no es simplemente [es Derrida quien subraya] un pensamiento de la reunión» (Derrida, 2008, 147). No lo es «simplemente», lo es sin serlo, quizá lo «es» en los márgenes, manteniéndose en una «ambigüedad frente a la metafísica de la presencia y del logocentrismo» (Derrida, 1986, 30). Ahora bien, Derrida señala este «no simplemente» apelando al texto Was heisst Denken? en el que, precisamente, Heidegger plantea la cuestión de la relación entre pensar y «Gedächtnis», así como de la llamada (heisst) en cuanto «convocación» y «promesa» de lo que (se) da a pensar. Heidegger plantea así un pensamiento del don y del «Es gibt» del que Derrida, tomando la frase paródica de Paul de Man, «die Sprache verspricht (sich)», señala que, hasta cierto punto, ésta puede inscribirse en el texto heideggeriano, es decir, que hasta cierto punto la «Andenken-Gedächtnis» se constituiría en Heidegger como promesa imposible y, por tanto, como lo absolutamente otro al recuerdo.

Derrida sostiene este «hasta cierto punto» aun cuando en Spectres de Marx expresa sus profundas dudas sobre si la memoria en cuanto «Versammlung», es decir, reunión del pensamiento, puede abrirse a lo heterogéneo del recuerdo, a lo absolutamente anacrónico y, por tanto, si la «mémoire» en cuanto apertura a la venida del arribante no consiste precisamente en lo opuesto a la memoria heideggeriana (Cfr. Derrida, 1995a, 41). La «memoria» como «Andenken-Gedächtnis», como pensamiento (Gedanke) de la reunión (Versammlung) en la Diferencia (Unter-Schied), anularía la irrupción heterogénea del otro, la enmarcaría en el «venir a presencia» (Anwesenheit) y, por tanto, negaría el acontecimiento (événement). Por el contrario, la «mémoire» en cuanto «avenir» del «arrivant» no puede sino mantenerse en la apertura a la absoluta «anacronía», en el sin-horizonte, en el desierto y en la dislocación del tiempo que Heidegger, en Zeit und Sein, pretendía conjurar a través de la unidad de un «tiempo auténtico tetradimensional», algo que Derrida discute planteando que quizá sea el concepto de «concepto de tiempo», propio o impropio, el que imposibilita pensar una memoria como porvenir, una memoria como lo otro del recuerdo (Cfr. Derrida, 1994, 97-102).

En este sentido, efectivamente, al establecer Heidegger la «Versammlung», el «legein», el «'En» como objetos de la memoria, por más aporéticos e imposibles que estos resulten; al considerar que la presencia se entrega «en mano», se mantendría en «el» pensamiento metafísico, casi con la conciencia tranquila. La «memoria» en Derrida lo es «de» la huella $\mathrm{y}$ «de» los espectros $\mathrm{y}$, por tanto, nunca «sucede», no puede llegar a «suceder» $\mathrm{y}$, por eso mismo, no deja nunca de «sucederse». Hasta qué punto esto pueda inscribirse todavía en el pensamiento heideggeriano, en su «Sprache spricht» que no «verspricht (sich)» sólo podría resolverse si fuese aquietada, revelada en una «Aufhebung» la relación infinitamente discreta «entre» Heidegger y Derrida. Por tanto, como señala este último, «la cuestión es finalmente sobre el énfasis, la insistencia, la medida y el acento. Y aquí, incontestablemente, Heidegger acentúa la reunión» (Derrida, 2001, 118). Este «incontestablemente», sin embargo, recogería un tono más propio de Heidegger que de Derrida, quien pocas páginas antes afirma: 
Yo estoy del lado de la dislocación, de la dispersión, de la diseminación. Sería injusto y simplificador decir que Heidegger violenta la diferencia, la dislocación, la diseminación: se podría realizar una lectura de Heidegger que mostrara que hay en él todo un pensamiento de la dislocación. Pero hay una fuerza allí que permanece del lado de la reunión, del ser junto o próximo a sí (Derrida, 2001, 116)

La cuestión de la memoria, la posibilidad de un acercamiento entre Heidegger y Derrida deviene, en definitiva, una cuestión de tono, de acento, algo que, como confiesa Derrida, siempre le ha preocupado más que el contenido o el fondo mismo ( $C f r$. Derrida, 1997b, 70). Ahora bien, esta es una cuestión que, más que resolver la lectura de estos textos, conduciría a un análisis de la «Stimmung» heideggeriana y la «Verstimmung» que plantea Derrida como «posibilidad para el otro tono, o para el tono del otro» (Derrida, 2003b, 54), la dislocación del «oído filosófico», de esa superficie tensa omniabarcante que es el tímpano. El cierre de la aproximación a través de la cuestión de la memoria en Heidegger y Derrida no llega a consumarse en una «Versammlung» que aquiete la diferencia entre ambos: no hay sino recuerdos aplazados, desplazados. En definitiva, no hay recuerdo de la cuestión de la memoria como confrontación entre Heidegger y Derrida, sino una memoria prometida. Si la memoria lo es del porvenir, el recuerdo de los textos de Heidegger y de Derrida no puede conducir sino a la obligación de continuar leyendo, a prometer una respuesta imposible.

\section{Bibliografía}

Barash, J. A. (2008): «Heidegger and the Metaphysics of Memory», Studia Phenomenologica, VIII, pp. 401-409.

Derrida, J. (1974): Glas. Paris. Galilée.

Derrida, J. (1985): La voz y el fenómeno. Valencia. Pre-Textos.

Derrida, J. (1986): De la gramatología. Madrid, Siglo Veintiuno.

Derrida, J. (1987): Psyché. Inventions de l'autre. Paris. Galilée.

Derrida, J. (1993): Points de suspension. Paris. Galilée.

Derrida, J. (1994): Márgenes de la filosofía. Madrid. Ediciones Cátedra.

Derrida, J. (1995a): Espectros de Marx. Madrid. Editorial Trotta.

Derrida, J. (1995b): Dar (el) tiempo. I. La moneda falsa. Barcelona. Paidós Ibérica.

Derrida, J. (1997a): Mal de archivo. Madrid. Editorial Trotta.

Derrida, J. (1997b): El monolingüismo del otro. Buenos Aires. Ediciones Manantial.

Derrida, J. (1998a): Aporías. Morir - esperarse (en) los “límites de la verdad”. Barcelona. Paidós Ibérica.

Derrida, J. (1998b): Ecografías de la televisión. Buenos Aires. EUDEBA.

Derrida, J. (1998c): Políticas de la amistad seguido de El oído de Heidegger. Madrid. Editorial Trotta.

Derrida, J. (2000): Dar la muerte. Barcelona. Paidós Ibérica Derrida, J. (2001) ¡Palabra! Instantáneas filosóficas. Madrid. Editorial Trotta.

Derrida, J. (2001): «Entretien», en: J. Janicaud. Heidegger en France II. Entretiens, Paris: Albin Michel.

Derrida, J. (2002): Schibboleth. Para Paul Celan. Madrid. Editora Nacional. 
Derrida, J. (2003a): Papel Máquina. Madrid. Editorial Trotta.

Derrida, J. (2003b): Sobre un tono apocalíptico adoptado recientemente en filosofía. Buenos Aires. Siglo Veintiuno.

Derrida, J. (2008): Memorias para Paul de Man. Barcelona, Editorial Gedisa.

Derrida, J. (2009a): La difunta ceniza. Buenos Aires. Ediciones La Cebra.

Derrida, J. (2009b): Otobiografías. La enseñanza de Nietzsche y la política del nombre propio. Buenos Aires. Amorrortu Editores.

Derrida, J. (2011): Salvo el nombre. Buenos Aires. Amorrortu editores.

Esposito, C. (2009): «Heidegger y Agustín. La memoria, la tentación, el tiempo», Pensamiento $65, \mathrm{n}^{\circ} .245$. pp. 433-462.

Gadamer, H.-G. (1999) «Thinking and Poetizing in Heidegger and in Hölderlin's “Andenken”», en Risser, J. (ed.) (1999): Heidegger toward the Turn. Albany. State University of New York Press. pp. 145-163

Haar, M. (1993): The Song of the Earth. Bloomington. Indiana University Press.

Heidegger, M. (1976). Wegmarken, GA 9. Frankfurt am Main, Vittorio Klostermann.

Heidegger, M. (1977a): Sein und Zeit, GA2. Frankfurt am Main. Vittorio Klostermann.

Heidegger, M. (1977b): Holzwege GA 5. Frankfurt am Main. Vittorio Klostermann.

Heidegger, M. (1981): Erläureungen zu Hölderlins Dichtung, GA 4. Frankfurt am Main. Vittorio Klostermann.

Heidegger, M. (1985): Unterwegs zur Sprache, GA 12. Frankfurt am Main. Vittorio Klostermann.

Heidegger, M. (1989): Beiträge zur Philosophie, GA 65. Frankfurt am Main. Vittorio Klostermann.

Heidegger, M. (1991): Grundbegriffe, GA 51. Frankfurt am Main. Vittorio Klostermann.

Heidegger, M. (1993): Hölderlins Hymmne »Der Ister«, GA 53. Frankfurt am Main. Vittorio Klostermann.

Heidegger, M. (1997a): Nietzsche, GA 6.1. Frankfurt am Main. Vittorio Klostermann.

Heidegger, M. (1997b): Der Satz vom Grund, GA 10. Frankfurt am Main. Vittorio Klostermann.

Heidegger, M. (1999): Hölderlins Hymnen »Germanien« und »Der Rhein«, GA 39. Frankfurt am Main. Vittorio Klostermann.

Heidegger, M. (2000): Vorträge und Aufsätze, GA 7. Frankfurt am Main. Vittorio Klostermann

Heidegger, M. (2002): Was Heiss Denken?, GA 8. Frankfurt am Main. Vittorio Klostermann. Heidegger, M. (2005): Über der Anfang, GA 70. Frankfurt am Main. Vittorio Klostermann. McNeill, W. (1999): «Heimat: Heidegger on the Threshold», en Risser, J. (ed.) (1999): Heidegger toward the Turn. Albany. State University of New York Press. pp. 319-351.

Krell, D. F. (1990): Of Memory, Reminiscence, and Writing. On the Verge. Bloomington and Indianapolis. Indiana University Press.

Rocha de la Torre, A. (2012): «Tierra natal: entre agonía y afirmación de la diferencia», Revista de Filosofía vol. 37. n. 1. pp. 37-55

Wood, R. E. (2015): «The heart in Heidegger's thought», Continental Philosophy Review, vol. 48, Issue 4, pp. 445-462. 
